\title{
4D Sonographic Assessment of Intertwin Contacts
}

Pilar Prats, Bernat Serra, Sofia Fournier, Sonia Baulies, Wiku Andonotopo, Asim Kurjak

\section{ABSTRACT}

Objective: To assess the onset and frequency of first interfetal contacts by 4D sonography.

Subjects and methods: Twenty twin pregnancies were scanned transvaginally between 56 (8 weeks) and 69 postmenstrual days ( $9+6$ weeks) and onward transabdominally, at weekly intervals until 112 postmenstrual days (16 weeks). Scans were recorded on DVD and analyzed retrospectively. The moment of onset, type and frequency of intertwin contacts were assessed.

Results: First interhuman contacts were observed between 61 $(8+5$ weeks $)$ and $68(9+5$ weeks) postmenstrual days. The frequency of different movements varied according to the gestational age. 'Touch no reaction' and 'First reaction' were common and frequent from 70 postmenstrual days (10 weeks) onward. 'Slow body movements' were more common than 'Fast body movements'. 'Complex contacts' were more frequent at 94 postmenstrual days $(13+3$ weeks). Simple contacts diminished around 100 postmenstrual days (14+2 weeks). 'Complex contacts' and 'diffuse interactions' were more commonly observed between 105 (15 weeks) and 112 postmenstrual days (16 weeks). No significant differences were found when different gender combinations were compared.

Conclusion: Intertwin contacts start as soon as $8+5$ weeks of gestation and complex or diffuse interactions are already seen at 15 to 16 weeks of gestation.

Keywords: Fetal neurological development, Twins, 4D, Fetal behavior.

How to cite this article: Prats $P$, Serra B, Fournier S, Baulies S, Andonotopo W, Kurjak A. 4D Sonographic Assessment of Intertwin Contacts. Donald School J Ultrasound Obstet Gynecol 2012;6(2):154-159.

\section{Source of support: Nil}

Conflict of interest: None declared

\section{INTRODUCTION}

Fetal activity has been used as a sign of fetal viability since ancient times. The sum of all fetal activity is called 'fetal behavior'.

With the development of transabdominal, twodimensional ultrasound, fetal movements were recognized as developing during the first trimester.

Reinold was one of the first to describe fetal activity with two-dimensional sonography. ${ }^{1}$ Nine years later, De Vries et al evaluated the onset and development of fetal activity using video documentation. They described different types of fetal activity according to their onset in singleton pregnancies. ${ }^{2}$ In the 1950s, Hooker showed that the embryo responds to stimuli. ${ }^{3}$ Spontaneous activity is the dominant behavioral pattern in singleton pregnancies. However, external stimuli (mother activity, glucose intake, exposure to drugs, alcohol, nicotine, caffeine or maternal stress) can also trigger fetal motor activity.

Hooker suggested that the activity of a twin could be either spontaneous or induced by the cotwin, and this hypothesis was confirmed by Arabin et al who reported embryonic reaction toward a tactile stimulus between 8 and 9 weeks of gestation. In more advanced pregnancies, they defined the quality of intertwin contacts as 'first reach and touch', 'first reaction', 'complex contacts', 'mouth contacts' and 'diffuse interactions' 4 .

Twin pregnancies allow the first reactions toward touch to be observed in utero.

Despite the studies by Arabin et al, however, fetal behavior in twin pregnancies has been little investigated, ${ }^{5-10}$ particularly during the first half of gestation.

The problem of assessment with two-dimensional sonography is that all activity outside the transducer's field of view is ignored. The use of four-dimensional ultrasound has enabled to see a much larger field of view ${ }^{11}$ (Fig. 1).

Although there are reports in the literature studying fetal behavior with 4D sonography in single pregnancies, ${ }^{12-18}$ there is a lack of studies concerning twin pregnancies. Our aim was therefore to assess the onset and frequency of first interfetal contacts by 4D sonography. Here, we present a preliminary study of the onset and frequency of the first interhuman contacts.

\section{METHODS}

We conducted a descriptive and prospective study of 20 women with twin pregnancies, all of whom volunteered to take part. Oral informed consent was obtained from all the women. Inclusion criteria were the presence of a viable twin pregnancy prior to 8 weeks gestation, no concomitant use of prescribed drugs by the mother, and no significant difference in size between the twins.

A Voluson 730 Expert scanner (GE Medical Systems, Kretz Ultrasound, ZIPF, Austria) was used for explorations with the vaginal probe in 4D/real time (RAB $5 \mathrm{MHz}$ ) and the abdominal probe in 4D/real time (RAB 4-8 MHz). The examinations were limited to 20 minutes and were performed between 15:00 and 21:00, by the same investigator. Patients were scanned transvaginally between 56 (8 weeks) and 69 postmenstrual days (9+6 weeks), and 


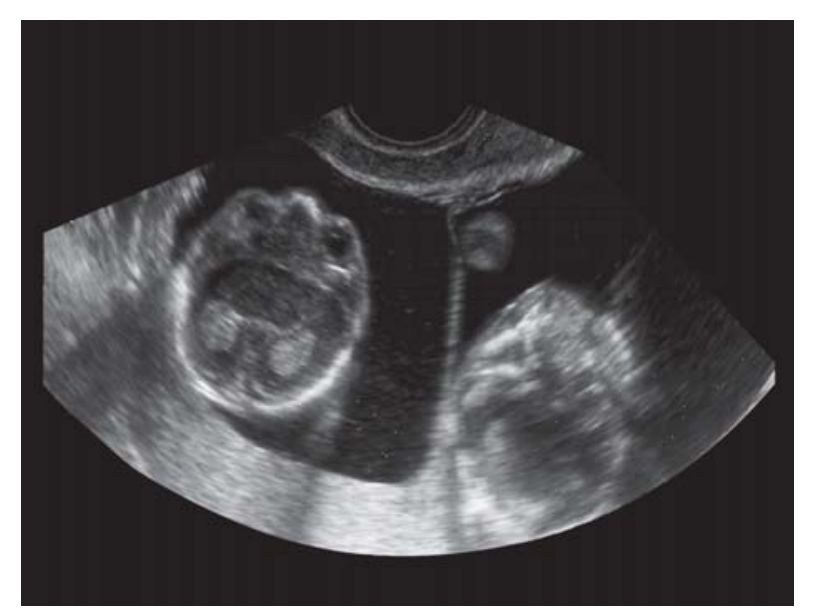

then abdominally from 70 postmenstrual days (10 weeks) onward and at weekly intervals until 112 postmenstrual days (16 weeks).

Ultrasound explorations were recorded on DVD and analyzed retrospectively. All cases were scanned weekly and the exploration was limited always to 20 minutes.

The DVDs of each twin pair were analyzed by two researchers. After a training period, the intra- and interobserver variability were calculated using the analysis of two different twin series.

For the observed intertwin contacts, a variation coefficient between 91 and 100\% was reached.

Gestational age and chorionicity were established at the earliest first trimester scan. Of the 20 twin pregnancies, three were monochorionic, all of them biamniotic, and 17 dichorionic. All monochorionic pairs and five of the dichorionic pairs were spontaneous, whereas the remaining 12 pregnancies were pregnancies achieved by ART.

According to their position on the screen, twins were characterized as either A, left/below or B, right/above. The sex of the fetuses was diagnosed as early as possible and correlated to their position.

Onset of intertwin contacts and their categorization ${ }^{4}$ was retrospectively done analyzing the recorded explorations.

Following movement patterns were differentiated:

1. First reach and touch: Twins touch each other without evidence of reaction.

2. First reaction: First movement of the cotwin within 1 second of touch. Thereafter, the speed of the primary contact is classified as slow or fast body contact. All short contacts following an action-reaction model were called primary contacts (short contact of $<5$ seconds following an action reaction model).

3. Complex contact: Contact of $>5$ seconds whereby action and reaction might be repetitive. Initiatives cannot always be correlated to one particular twin. Both bodies including extremities may be involved in this 'complex contact'.

4. Mouth contact: Initiating twin may also touch the head or mouth of the cotwin with the lips, followed by a reaction of the cotwin.

5. Diffuse interactions: Initiations and reactions which are difficult to distinguish (with advancing gestational age).

The data set was completed retrospectively and included data of pregnancy, delivery and perinatal outcome.

For statistical analysis, data were expressed in boxwhisker plots. The mean values and the 25th and 75th centiles were plotted up to 1.5-fold distances from the given centiles. Quantitative variables were compared with 
nonparametric tests (Kruskal-Wallis). All statistical analyses were performed with SPSS version 14.0. All tests were bilateral and significance was set at a p-value of 0.05 .

\section{RESULTS}

We observed that many forms of movement start within few days. The mean for touch no reaction, first reaction and slow body movements was 91 postmenstrual days (13 weeks), for fast body movements it was 92 postmenstrual days (13+1 weeks), and for more complex contacts it was between 93 and 95 days (13+2-13+4 weeks) (Fig. 2).

With increasing gestational age a higher frequency of movement was observed. Curiously, the frequency of 'first touch no reaction' (Fig. 3) increased only up to 13 weeks, but from then on stabilized or even diminished.

In the case of first reactions, which we divided into slow (Fig. 4) and fast (Fig. 5) body movements, it is interesting to observe that slow movements were always more common than fast movements at the studied period, that is between 8 and 16 weeks of pregnancy.

However, the graphics reveal that the complexity of intertwin contacts increases from 84 postmenstrual days (12 weeks) onward. Complex contacts (Fig. 6) and diffuse interactions (Fig. 7) were observed more often among older fetuses.

The frequency of mouth contacts, considered very complex contacts and not observed until the 10th week of gestation, increases during pregnancy up to an average of eight movements at 16 weeks of pregnancy (Fig. 8). That is, as gestational age progresses, the movements become more complex and occur more frequently.

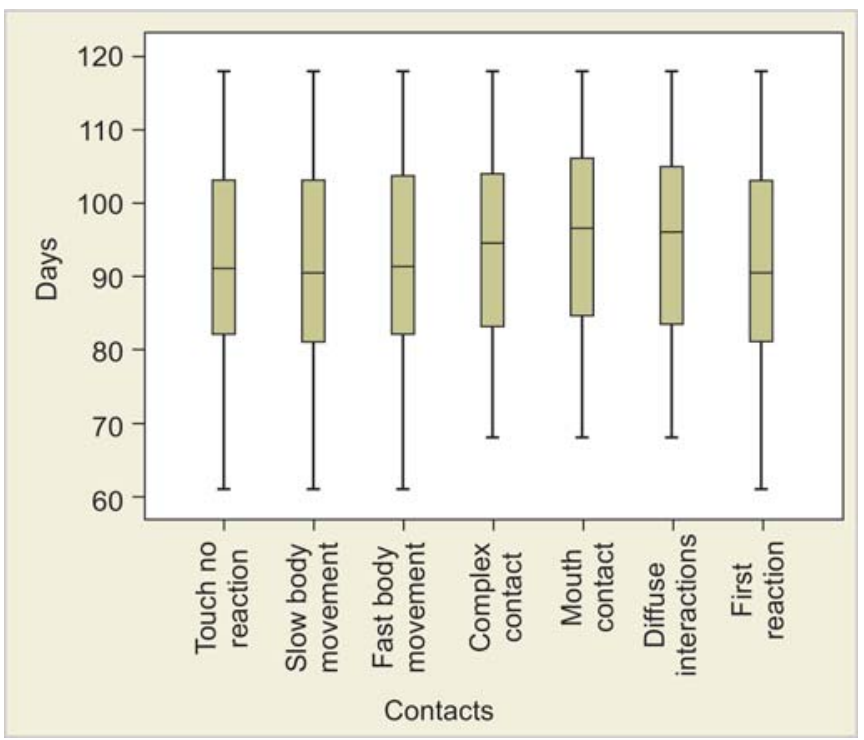

Fig. 2: Onset of intertwin contacts assessed with 4D sonography

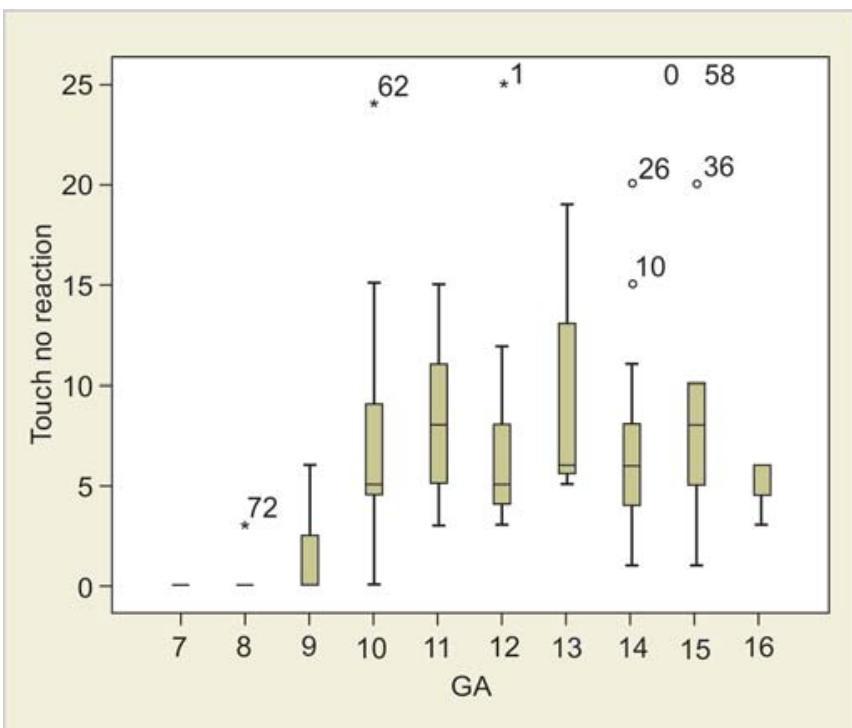

Fig. 3: Distribution of first reach and touch in the study group

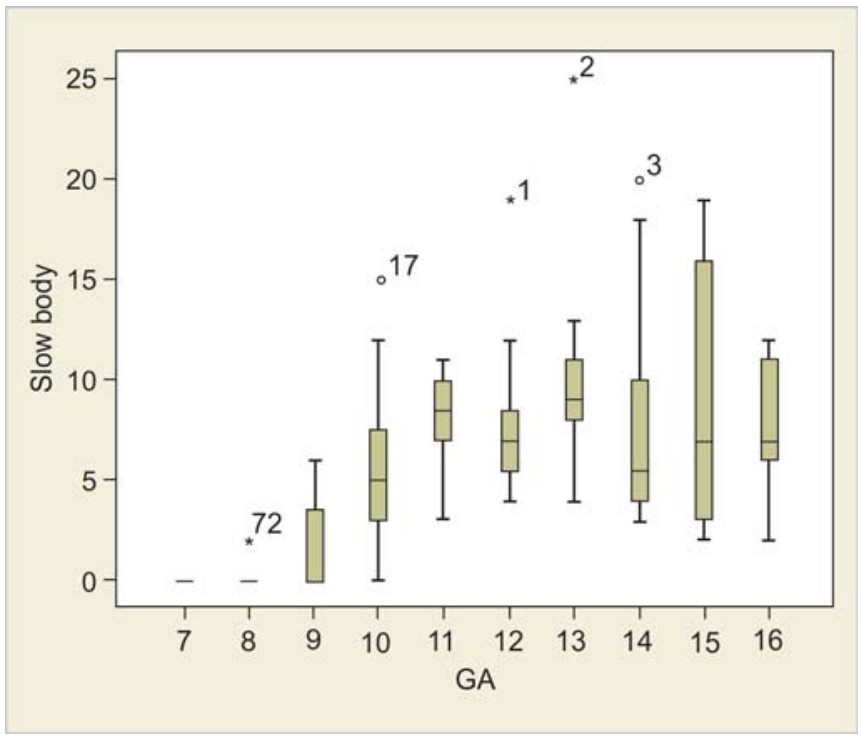

Fig. 4: Distribution of slow body movements in the study group

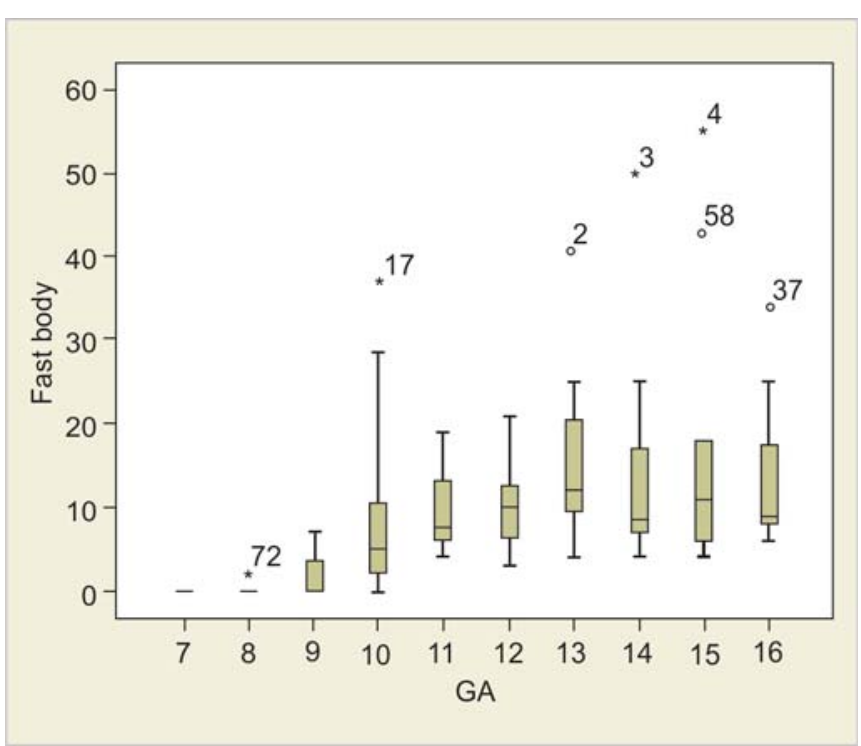

Fig. 5: Distribution of fast body movements in the study group 


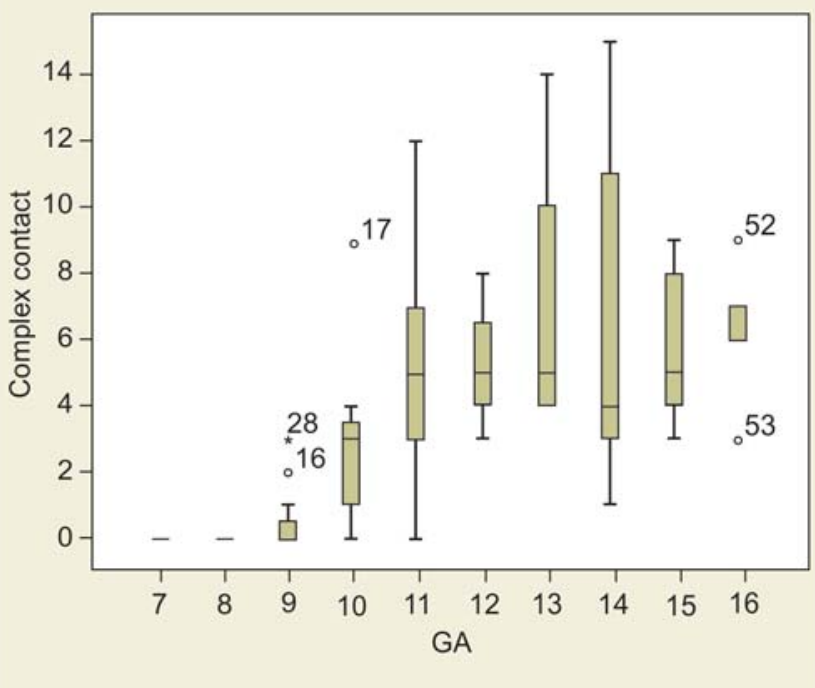

Fig. 6: Distribution of complex contacts in the study group

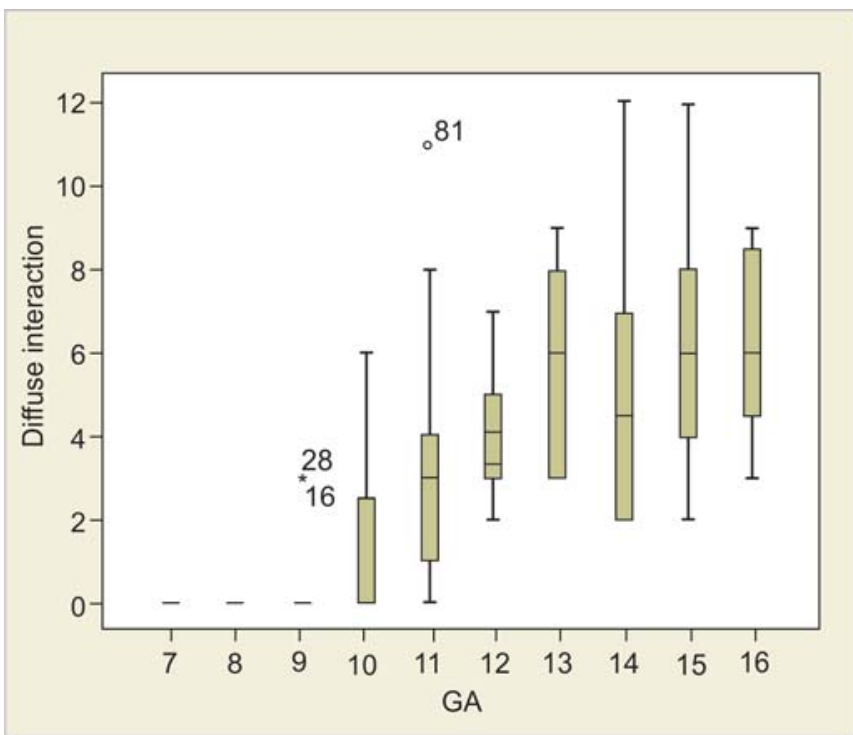

Fig. 7: Distribution of diffuse interactions in the study group

Although we analyzed the subgroups according to different gender combinations, we did not detect differences in the onset of intertwin contacts (Table 1). It remains unknown whether with a larger series differences would

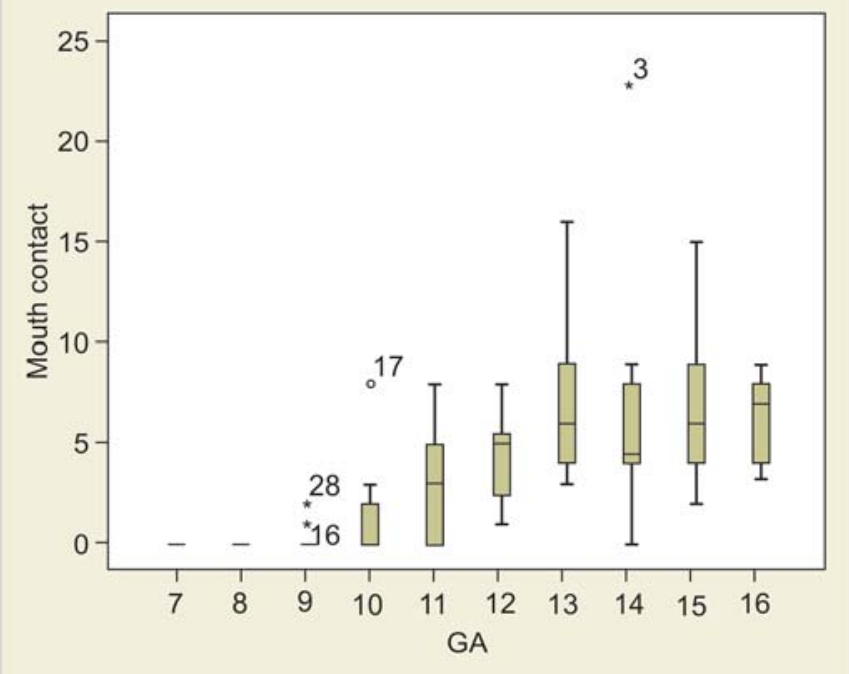

Fig. 8: Distribution of mouth contacts in the study group Note: (Figs 3 to 8 ) - ${ }^{\circ}$ : outliers, cases at more than $1.5 \times$ interquartile range from the nearest quartile; *: Extreme values—cases at more than $2 \times$ interquartile range from the nearest quartile

have appeared, as a (nonsignificant) tendency for the female/ female pairs to show earlier intertwin contacts was found.

\section{DISCUSSION}

Until recently, prenatal behavior in twins has only been studied with two-dimensional sonography and most studies were performed in advanced pregnancies. ${ }^{4-10,18,19}$

Two types of motor activity are possible in multiples: Spontaneous and reactive. Spontaneous motor activity is defined as embryonic or fetal activity that is not evoked by internal or external stimuli. Activity that is reactive to intertwin contacts is characterized as stimulated activity. Spontaneous motor activity precedes stimulated activity in terms of gestational age of onset. ${ }^{20}$

It is assumed that spontaneous motility and reactions toward stimuli are expressions of early neuromuscular development and that both have some kind of influence on the differentiation of the neuromuscular system. As with motor activity in singletons, the primacy of contact patterns may indicate that contacts are developed before they can

Table 1: Contacts according to gender combinations

\begin{tabular}{|c|c|c|c|c|c|c|c|}
\hline \multirow[b]{3}{*}{ Kind of contact } & \multicolumn{6}{|c|}{ Gender combination } & \multirow[b]{3}{*}{$p$-value* } \\
\hline & \multicolumn{2}{|c|}{ Female/male } & \multicolumn{2}{|c|}{ Female/female } & \multicolumn{2}{|c|}{ Male/male } & \\
\hline & Mean & $S D$ & Mean & $S D$ & Mean & $S D$ & \\
\hline Touch no reaction & 94.5 & 14.4 & 89.4 & 16.8 & 91.5 & 12.6 & 0.510 \\
\hline Slow body movement & 94.5 & 14.4 & 89.4 & 16.8 & 90.2 & 13.7 & 0.489 \\
\hline Fast body movement & 94.5 & 14.4 & 89.4 & 16.8 & 92.5 & 12.1 & 0.518 \\
\hline Complex contact & 96.0 & 14.0 & 91.5 & 15.7 & 92.5 & 12.1 & 0.560 \\
\hline Mouth contact & 95.8 & 14.2 & 95.4 & 15.4 & 95.0 & 9.7 & 0.951 \\
\hline Diffuse interactions & 96.0 & 14.0 & 92.9 & 15.5 & 95.0 & 9.7 & 0.792 \\
\hline First reaction & 94.5 & 14.4 & 89.4 & 16.8 & 90.2 & 13.7 & 0.489 \\
\hline
\end{tabular}

*Kruskal-Wallis test 
be used for responding to biological or psychological sensory stimuli. ${ }^{21}$

The initial development of axodendritic and axosomatic synapses occurs between 8 and 10 gestational weeks. ${ }^{22}$ Another striking increase in the number of axosomatic synapses is then reported to take place between 12 and 15 gestational weeks. This could be related to the increased incidence of more complex movements that fetuses show at these gestational ages.

$4 \mathrm{D}$ sonography increases the efficacy of the assessment of complex movements as it encompasses a much larger field as 2D sonography does. It also provides near real time spatial visualization of the fetal anatomy and movements and this simultaneous visualization of the entire anatomy of the two fetuses allows a more reliable characterization of the type of movement, whether isolated or in the context of intertwin contacts and interactions.

The assessment of the onset and frequency of first interfetal contacts by 4D sonography was the aim of the present study and we believe that the evaluation of twin behavior with 4D sonography enhances the visualization of movement activity of each fetus, independently of its spontaneous or reactive nature. In this study, we did not analyze the differences in activity patterns of cotwins.

Using 4D sonography, we observed the first intertwin contacts at $61(8+5$ weeks) postmenstrual days, while complex movements were seen from 68 postmenstrual days $(9+5$ weeks) onward. These results are quite different from those reported in studies done with 2D sonography. In these latter, the onset of first interfetal contacts seem to appear earlier and this probably reflects the better field of view offered by 4D over 2D sonography.

With 4D ultrasound, the onset of simple and complex interfetal contacts seem to occur almost at the same time. Nevertheless, simple movements are more often seen at earlier gestational ages. The complexity of intertwin contacts increases from 84 postmenstrual days (12 weeks) onward. With advancing gestational age and diminishing distance between twins, more complex contacts are seen.

The more complex interactions develop very quickly after the simplest ones, just few days later.

Although the aim of the study of the onset and frequency of first interfetal contacts by 4D sonography is to evaluate the fetal behavior in twins, it provides interesting information regarding the interpretation of fetal neurosensitive and neuromotoric activity. But there are many questions that remain unanswered.

The present research constitutes a pilot study and there is much more work to be done. Indeed, we are aware that the sample size is small (low statistical power), the duration of the explorations and the intervals between examinations could have been shorter. Furthermore, information regarding health or emotional state of the mother, the last food intake, etc. were not taken into account when analyzing the movements.

\section{REFERENCES}

1. Reinold E. Clinical value of fetal spontaneous movements in early pregnancy. J Perinat Med 1973;1:65-72.

2. de Vries JI, Visser GH, Prechtl HF. The emergence of fetal behavior. I Qualitative aspects. Early Hum Dev 1982;7:301-22.

3. Hooker D. The prenatal origin of behavior. Kansas: University of Kansas Press, 1952.

4. Arabin B, Bos R, Rijlaarsdam R, Mohnhaupt A, van Eyck J. The onset of inter-human contacts. Longitudinal ultrasound observations in early twin pregnancies. Ultrasound Obstet Gynecol 1996;8:166-73.

5. Arabin B, Gembruch U, et al. Intrauterine behavior. In Keith DM, Luke B (Ed). Multiple pregnancy: Epidemiology, gestation and perinatal outcome. New York: Parthenon Publishing 1995:331-49.

6. Arabin B, Gembruch U, et al. Registration of fetal behaviour in multiple pregnancy. J Perinat Med 1993;21(4):285-94.

7. Piontelli A, Bocconi L, Kustermann A, Tassis B, Zoppini C, Nicolini U. Patterns of evoked behavior in twin pregnancies during the first 22 weeks of gestation. Early Hum Dev 1997;50:39-45

8. Samueloff A, Younis J, et al. Incidence of spontaneous and evoked fetal movements in the first half of twin pregnancy. Gynecol Obstet Invest 1991;31:200-03.

9. Gallagher MW, Costigan K, Johnson TRB. Fetal heart accelerations, fetal movement and fetal behavior patterns in twin gestations. Am J Obstet Gynecol 1992;167:1140-44.

10. Sadowsky E, Ohel G, Simon A. Ultrasonographic evaluation of the incidence of simultaneous and independent movements in twin fetuses. Gynecol Obstet Invest 1987;25:5-9.

11. Lee A. Four-dimensional ultrasound in prenatal diagnosis: Leading edge in imaging technology. Ultrasound Rev Obstet Gynecol 2001;1:144-48.

12. Campbell S. 4D, or not 4D: That is the question. Ultrasound Obstet Gynecol 2002;19:1-4.

13. Kurjak A, Azumendi G, Vecek N, et al. Fetal hand movements and facial expression in normal pregnancy studied by fourdimensional sonography. J Perinat Med 2003;31:496-508.

14. Kurjak A, Stanojevic M, Andonotopo W, Salihagic-Kadic A, Carrera JM, Azumendi G. Behavioral pattern continuity from prenatal to postnatal life: A study by four-dimensional (4D) ultrasonography. J Perinat Med 2004;32:346-53.

15. Kurjak A, Stanojevic M, Azumendi G, Carrera JM. The potential of four-dimensional (4D) ultrasonography in the assessment of fetal awareness. J Perinat Med 2005;33:46-53.

16. Kurjak A, Vecek N, Azumendi G, et al. Fetal behaviour by 4D sonography. Ultrasound Rev Obstet Gynecol 2003;3:300-09.

17. Kurjak A, Andonotopo W, Radakovic B, Stanojevic M. Recent advances in the assessment of multifetal pregnancies by 3D/4D sonography. Gynaecol Perinatol 2006;15(3):119-30.

18. Zimmer EZ, Goldstein I, Aglay S. Simultaneous recording of fetal breathing movements and body movements in twin pregnancy. J Perinat Med 1988;16:109-12.

19. Piontelli A. A study on twins before and after birth. Int Rev Psycho Anal 1989;16:413. 
20. Vecek N, Kurjak A, Azumendi G. Fetal behaviour in multiple pregnancies studied by four-dimensional sonography. Ultrasound Rev Obstet Gynecol 2004;4:52-58.

21. Prechtl HFR. Continuity of change in early neural development. In: Prechtl HFR (Ed). Continuity of neural functions form prenatal to postnatal life. Oxford: Blackwell Scientific Publication, Philadelphia: JB Lippincott 1984;1-15.

22. Okado N. Development of the human cervical spinal cord with reference to synapse formation in the motor nucleus. J Comp Neurol 1980;191:495-513.

\section{ABOUT THE AUTHORS}

\section{Pilar Prats}

Department of Obstetrics, Gynecology and Reproductive Medicine Institut Universitari Dexeus, Barcelona, Spain

\section{Bernat Serra}

Department of Obstetrics, Gynecology and Reproductive Medicine Institut Universitari Dexeus, Barcelona, Spain

\section{Sofia Fournier}

Department of Obstetrics, Gynecology and Reproductive Medicine Institut Universitari Dexeus, Barcelona, Spain

\section{Sonia Baulies}

Department of Obstetrics, Gynecology and Reproductive Medicine Institut Universitari Dexeus, Barcelona, Spain

\section{Wiku Andonotopo}

Fetomaternal Unit, Department of Obstetrics and Gynecology, Eka Hospital, Bumi Serpong Damai, Serpong, Banten and Fetomaternal Unit, Department of Obstetrics and Gynecology, Tangerang General Hospital, Banten, Indonesia

\section{Asim Kurjak}

Professor and Dean, Faculty of Health Science, Dubrovnik International University, Dubrovnik, Croatia

\section{CORRESPONDING AUTHOR}

Bernat Serra, Gran Via Carles III, 71-75, 08028 Barcelona, Spain Phone:+34932274705, e-mail: berser@dexeus.com 